\title{
Case of accelerated silicosis in a sandblaster
}

\author{
Beáta HUTYROVÁ ${ }^{1 *}$, Petra SMOLKOVÁ ${ }^{2}$, Marie NAKLÁdALOVÁ2, \\ Tomáš TICHÝ ${ }^{3}$ and Vítězslav KOLEK ${ }^{1}$
}

\author{
${ }^{1}$ Department of Respiratory Medicine, Faculty of Medicine and Dentistry, Palacký University Olomouc, Czech \\ Republic \\ ${ }^{2}$ Department of Occupational Medicine, Faculty of Medicine and Dentistry, Palacký University Olomouc, Czech \\ Republic \\ ${ }^{3}$ Department of Clinical and Molecular Pathology, Faculty of Medicine and Dentistry, Palacký University \\ Olomouc, Czech Republic
}

Received February 14, 2013 and accepted December 12, 2014

Published online in J-STAGE December 18, 2014

\begin{abstract}
Sandblasting is traditionally known as a high-risk profession for potential development of lung silicosis. Reported is a case of a sandblaster with confirmed accelerated silicosis, a condition rather rarely diagnosed in the Czech Republic. Initially, the patient presented with progressive dry cough and exertional dyspnoea. In the early diagnostic process, a possible occupational aetiology was considered given his occupational history and known high-risk exposure to respirable silica particles confirmed by industrial hygiene assessment at the patient's workplace. The condition was confirmed by clinical, histological and autopsy findings. The patient died during lung transplantation, less than five years from diagnosis.
\end{abstract}

Key words: Silica, Accelerated silicosis, Alveolar proteinosis, Silicoproteinosis, Sandblaster, Neuronspecific enolase (NSE), Lung transplantation, Whole lung lavage

\section{Introduction}

Silicosis is a fibrotic disease of the lungs caused by the inhalation and deposition of free crystalline silicon dioxide $\left(\mathrm{SiO}_{2}\right)$ or silica in the lung tissue ${ }^{1)}$. It falls into the group of pneumoconioses. Silica exposure has long been a wellknown occupational hazard in sandblasting, tunnelling, mining, but also in a range of other professions. Although silica-associated diseases are preventable, they remain common worldwide, particularly in developing countries ${ }^{2}$.

There are several clinical and pathologic varieties of silicosis, including acute silicosis, accelerated silicosis, chronic silicosis, and conglomerate silicosis (progressive

*To whom correspondence should be addressed.

E-mail: Beata.Hutyrova@fnol.cz

(C)2015 National Institute of Occupational Safety and Health massive fibrosis or complicated silicosis) $)^{3)}$. Development of different forms of silicosis is dependent on duration of exposure, concentration and the surface of silica particles ${ }^{4}$. Chronic (nodular) silicosis that develops after $10-20 \mathrm{yr}$ of exposure to silica is the most frequent form of the disease ${ }^{2)}$. Acute and accelerated silicosis are less common, particularly in developed countries. Acute silicosis is also referred to in the literature as silicoproteinosis or silicolipoproteinosis, because of its typical histological pattern of periodic acid-Schiff-positive lipoproteinaceous material in the alveoli, producing a picture of alveolar lipoproteinosis. Whereas acute silicosis occurs after intense short exposures within a few years after the initial exposure, accelerated silicosis develops within 5 to $10 \mathrm{yr}$ of initial exposure to silica dusts ${ }^{5-7)}$.

Radiologically, classic simple chronic silicosis is typically characterized by multiple nodular opacities with pre- 
dominance in the upper lobe and posterior part of the lung. With increased duration and intensity of exposure, the silicotic nodules expand and become confluent, resulting in a complicated form ${ }^{2}$. Enlargement of hilar and mediastinal lymph nodes with calcification at the periphery of the node is common ${ }^{7)}$. Accelerated silicosis may be radiologically similar to chronic silicosis, with more rapid development of changes following initial exposure. However, it may also possess features typical for acute silicosis ${ }^{5,8,9)}$. Patients with accelerated silicosis are at a higher risk of developing progressive massive fibrosis as well as other complications ${ }^{5,10)}$. In acute silicosis (silicolipoproteinosis), due to intra-alveolar accumulation of lipoproteinaceous material, bilateral consolidation, multifocal patchy groundglass opacities with perihilar distribution and centrilobular nodular opacities are usually described ${ }^{7)}$. Sometimes, a crazy-paving appearance is present.

Accelerated silicosis is similar to acute silicosis in developing alveolar lipoproteinosis with accumulation of granular lipoproteinaceous material containing alveolar surfactant in alveolar spaces and interstitial inflammation. In addition, accelerated silicosis is associated with the presence of silicotic nodules that develop sooner than in chronic silicosis ${ }^{2}$.

\section{Case Report}

A 38-yr-old man presented with progressive dry cough and dyspnoea on exertion of 6-month duration. His personal history indicated that he was a former smoker (10 pack-year cigarette smoking history). He completed his apprenticeship as a metal processor and worked in this profession for 2 yr. For the next ten years, he worked as a locksmith and then, for the last $5 \mathrm{yr}$ prior to his disease, as a sandblaster. He used compressed air and foundry sand containing high amounts of silicon dioxide to blast stainless steel materials before welding or welded products.

On admission, his physical examination was normal. A chest radiograph revealed a bilateral reticulonodular pattern. High-resolution computed tomography (HRCT) scans showed interstitial shadowing and diffuse small nodules, a subpleural reticular pattern and mediastinal lymphadenopathy in all areas (subcarinal lymph nodes $29 \times 20 \mathrm{~mm}$ ) (Fig. 1). The changes on HRCT scans had upper to mid zone predominance. Complete laboratory examination revealed positivity of antinuclear antibodies, increased levels of lactate dehydrogenase $(25.9 \mu \mathrm{kat} / \mathrm{l})$, gamma-glutamyl transferase $(2.8 \mu \mathrm{kat} / \mathrm{l})$, circulating immune complexes (89 U), soluble IL-2 receptor (1252 kU/1), IgA (6.6 g/l),

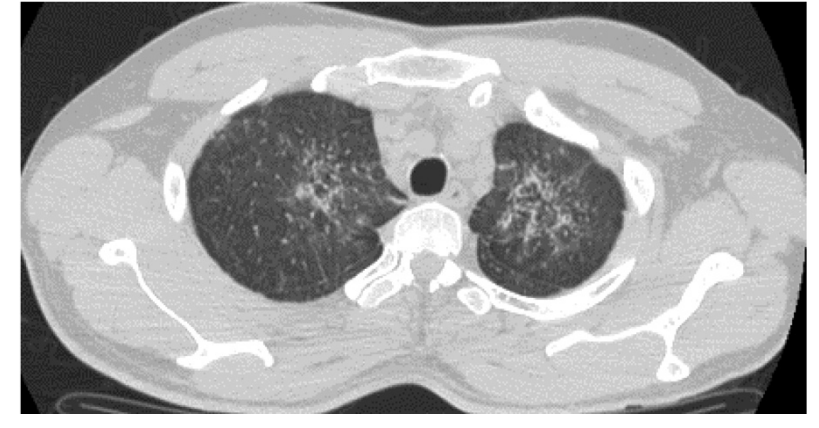

Fig. 1. HRCT scans at the initial presentation of the disease.

$\operatorname{IgG}(21.2 \mathrm{~g} / \mathrm{l}), \operatorname{IgE}(247 \mathrm{U})$ and tumour markers thymidine kinase (TK, $53.5 \mathrm{IU} / 1)$, tissue polypeptide antigen (TPA, $3.9 \mu \mathrm{g} / 1), \beta 2$-microglobulin $(5.4 \mathrm{mg} / \mathrm{l})$, neuron-specific enolase (NSE, $68.0 \mu \mathrm{g} / \mathrm{l}$ ) and cytokeratin fragment 19 (CYFRA 21-1, $7.7 \mu \mathrm{g} / \mathrm{l}$ ). Functional testing revealed mild restrictive ventilatory impairment $(\mathrm{VC} 3,550 \mathrm{ml}=76 \%$, FEV1 $3,000 \mathrm{ml}=80 \%, \mathrm{FEV} 1 / \mathrm{FVC}=84 \%, \mathrm{TLC}=67 \%$ ) and the diffusing capacity for carbon monoxide (DLCO) was moderately reduced (40\%). Bronchoscopy with bronchoalveolar lavage was performed which revealed a picture of chronic bronchitis. Cytology of bronchoalveolar lavage fluid (BALF) showed lymphocytic alveolitis with a slightly increased percentage of eosinophils (lymphocytes $46 \%$, eosinophils $1 \%$ and alveolar macrophages 53\%), numerous pigmentophages, crystals and PAS-positive amorphous material. The CD4/CD8 ratio was decreased (0.55). Polarized light microscopy examination of BALF revealed birefringent crystals that conformed to $\mathrm{SiO}_{2}$. Microbiological examination of BALF was negative.

Morphologically, transbronchial lung biopsy confirmed a combined picture of lymphocytic alveolitis and alveolar lipoproteinosis with a tiny silicotic nodule of up to $1 \mathrm{~mm}$. Diffuse fibrosis of the alveolar septa had not yet developed (Fig. 2). Under polarized light, numerous microcrystals resembling $\mathrm{SiO}_{2}$ were observed.

Six months later, HRCT showed slightly progressing bilateral diffuse interstitial thickening and diffuse nodules with a diameter $<2 \mathrm{~mm}$, and stationary mediastinal lymphadenopathy. Ventilatory impairment was worsened (VC $2,920 \mathrm{ml}=63 \%$, FEV1 2,370 $\mathrm{ml}=64 \%, \mathrm{FEV} 1 / \mathrm{FVC}=$ $85 \%$, TLC $=62 \%$ ), whereas DLCO was stationary $(42 \%)$. The patient underwent video-assisted thoracoscopic surgery with biopsy of the mediastinal lymph node and left upper lobe. Histological examination showed already diffuse fibrosis of the alveolar septa with intensive reaction of intra-alveolar macrophages and apparently resolved lymphocytic infiltrates. In some areas of the lung, alveolar 


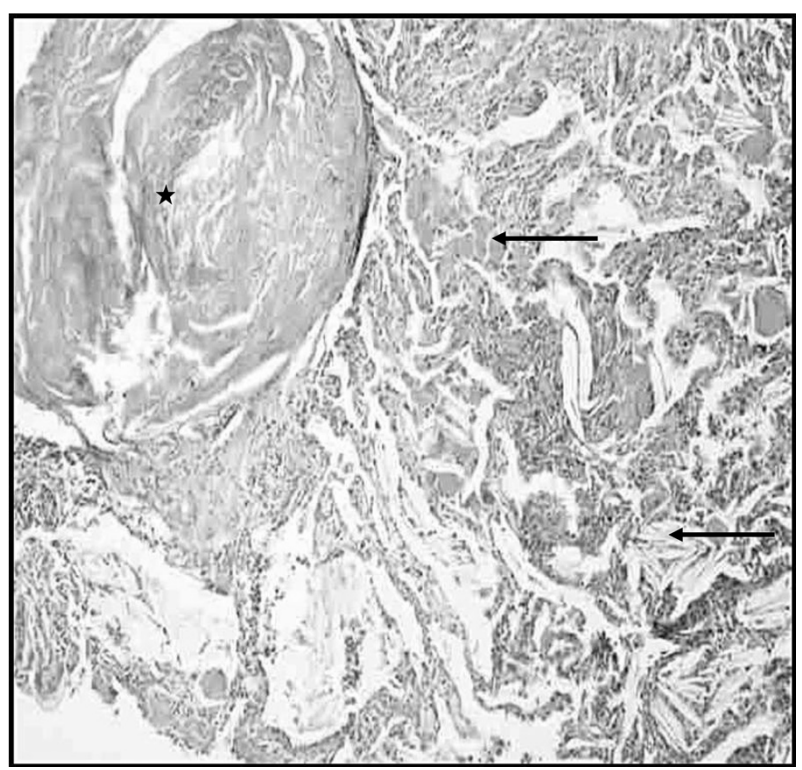

Fig. 2. Transbronchial lung biopsy.

The picture clearly shows a silicotic nodule (asterisk) and lung tissue with thickened alveolar septa infiltrated with lymphocytes and histiocytes. In the alveoli, PAS-positive protein material is present, corresponding to surfactant in alveolar lipoproteinosis (upper arrow). In some alveoli, there are optically empty spaces previously occupied by cholesterol crystals (lower arrow). PAS staining, 100× magnification.

lipoproteinosis persisted. Dispersed individual silicotic nodules of up to $1 \mathrm{~mm}$ were detected. In the subpleural region, compact fibrosis with numerous cholesterol crystals had developed (Fig. 3). The final histological findings were endogenous lipid pneumonia and alveolar lipoproteinosis with hyaline nodules suggesting silicosis. Clinically, the condition was defined as accelerated silicosis.

Given his occupational history and the fact that the patient worked as a sandblaster which put him at a risk for developing silicosis, after completion of the diagnostic process, industrial hygiene specialists were asked for objective assessment of professional exposure at his workplace. The assessment, completed approximately 10 months after clinical diagnosis had been made, concluded that the patient had worked for at least $3 \mathrm{yr}$ and 2 months (probably even as long as $5 \mathrm{yr}$ ) as a sandblaster in a small closed room with neither natural ventilation to the outside nor extraction. Moreover, for the first two years, he had only been equipped with a respirator instead of adequate protective wear such as an air-fed helmet with a filter. He had even been caught not wearing the protective helmet on three occasions. Foundry silica sand was found to contain $99 \%$ of $\mathrm{SiO}_{2}$. Blasting activity accounted for approximately $60 \%$ of his working time. Unfortunately, exact data on

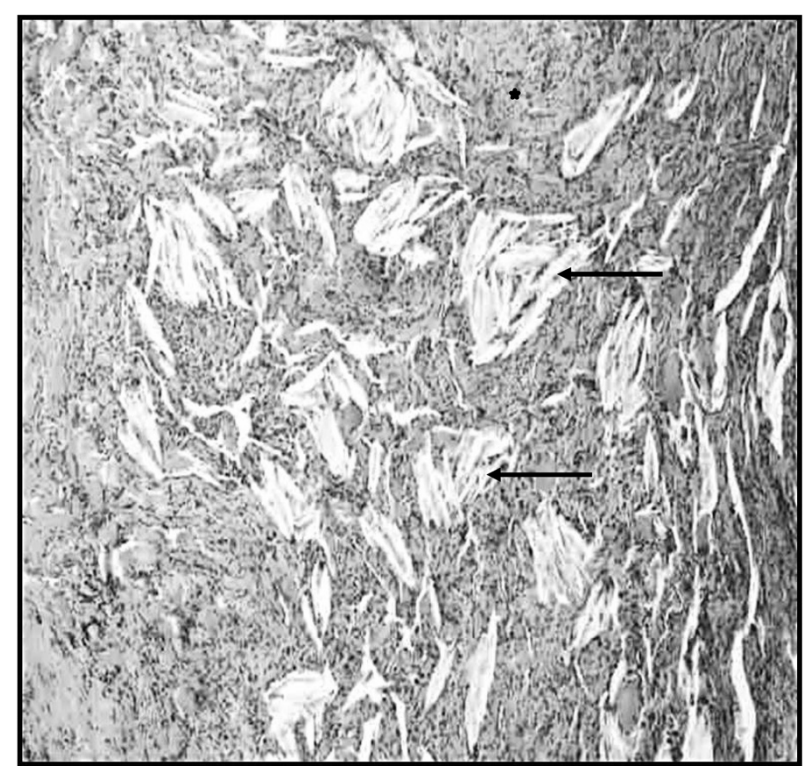

Fig. 3. VATS biopsy.

Approximately 6 months after transbronchial biopsy. The subpleural lung regions contain compact fibrotic lesions (asterisk) with numerous cholesterol crystals (arrows). HE staining, 200× magnification.

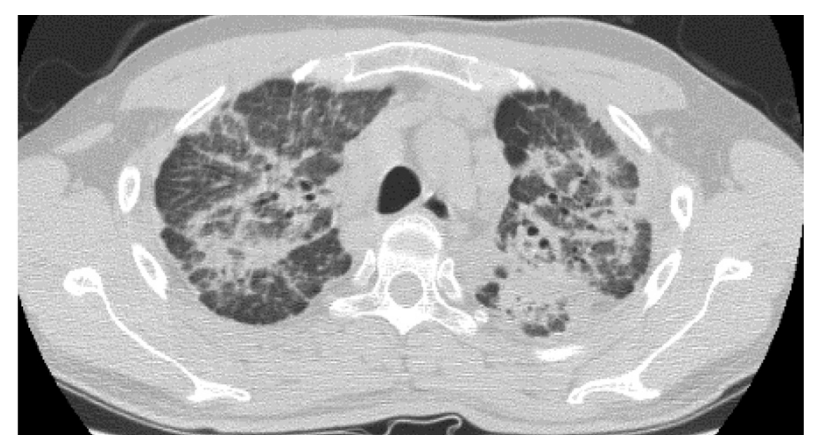

Fig. 4. HRCT scans after 2 years of disease progression.

dust loading associated with such massive exposure were unavailable as at the time of assessment, the method was no longer used. However, quantification of workplace risk conditions suggested a respirable fraction of $\mathrm{SiO}_{2}$ of approximately $0.3 \mathrm{mg} / \mathrm{m}^{3}$. With respect to the evidence and disease dynamics, the patient's condition was recognized as an occupational disease.

The patient was treated with systemic corticosteroids (prednisone $40 \mathrm{mg}$ daily initially) for 9 months. In the first $2 \mathrm{yr}$ of the disease, the patient had several infections of the upper and lower airways with fever and attacks of dry cough treated with antibiotics. After $2 \mathrm{yr}$, significant signs of disease progression were revealed by chest Xray and HRCT scans, with more pronounced mediastinal lymph node enlargement, diffuse ground-glass opacities, 
foci of consolidation, reticular pattern, nodules and pleural thickening (Fig. 4). The restrictive ventilatory impairment on spirometry was worsened (VC 2,100 $\mathrm{ml}=45 \%$, FEV1 $1,880 \mathrm{ml}=51 \%, \mathrm{FEV} 1 / \mathrm{VC}=90 \%, \mathrm{TLC}=50 \%) . \mathrm{DLCO}$ was moderately decreased $(\mathrm{DLCO}=44 \%, \mathrm{DLCO} / \mathrm{VA}=$ $76 \%$ ). During bronchoscopy, BALF with a slight milky appearance was obtained. The BALF cytological findings were similar to those in the initial phase of disease. The patient was diagnosed with exercise-induced hypoxemia and started on long-term home oxygen therapy. Due to the milky appearance of BALF and presence of ground-glass opacities on HRCT scans, progression of secondary alveolar proteinosis was considered. Therefore, whole lung lavage of the left lung was performed with $5,000 \mathrm{ml}$ of saline under general anaesthesia. This brought no improvement of symptoms and findings on chest radiograph; the functional parameters were even worse ( $\mathrm{VC}=40 \%$, FEV1 $=38 \%, \mathrm{FEV} 1 / \mathrm{VC}=76 \%, \mathrm{TLC}=46 \%$; DLCO $=33 \%$ ).

Considering the progression of the disease and the lack of treatment options, transplantation of the silicotic lung was indicated. Bilateral lung transplantation was performed. The patient died during the transplantation, less than five years from diagnosis, due to massive pulmonary embolism. Autopsy confirmed the diagnosis of advanced silicosis. At the autopsy, confluent hyaline silicotic nodules diffusely involving both lungs were observed. In the nodules multinucleated cells with cholesterol crystals were found. Furthermore, fibrosis of the alveolar septa and chronic inflammatory changes of the lung interstitium were present.

\section{Discussion}

Acute and accelerated silicosis are commonly associated with heavy exposure to silica dust and usually occur in sandblasting, silica flour milling, surface drilling, tunnelling and other crushing operations ${ }^{3}$. Sandblasting involves projecting a stream of abrasive particles, mostly silica sand, onto a target surface by compressed air or steam ${ }^{11)}$. It has been commonly used for abrasion of metal or glass. There have been reports of individual cases of accelerated silicosis in foundry and masonry industries, such as an interesting case of accelerated silicosis in small private agate mill workers in China ${ }^{12,13)}$.

To our knowledge, numerous cases of acute/accelerated silicosis in Turkish denim sandblasters have been reported since $2005^{8,9,11)}$. The common denominators of circumstances of occupational exposure were small plants with massive exposure to silica during sandblasting in closed and poorly ventilated rooms, long working hours and absence of adequate protective equipment ${ }^{11)}$. Histopathologically, accelerated silicosis is characterized by picture similar to acute silicosis with developing alveolar lipoproteinosis and interstitial inflammation, but in addition silicotic nodules are present ${ }^{2}$. Histological changes in our patient are similar to findings from lung biopsy described in two cases of acute silicosis in sandblasters ${ }^{11)}$. In the first case, silicotic nodule composed mainly of bundles of interlaced collagen with minimal inflammatory reaction and accumulation of lipoproteinaceous material within the alveoli were found. In the second case, exudative alveolar lipoproteinosis associated with chronic inflammation, thickening of alveolar septa with hypertrophic and hyperplastic type II epithelial cells were described. In our case of accelerated silicosis, two biopsies were performed. A combined picture of lymphocytic alveolitis and alveolar lipoproteinosis with a tiny silicotic nodule of up to $1 \mathrm{~mm}$ was present in the first transbronchial lung biopsy. 6 month later, histological examination showed already diffuse fibrosis of the alveolar septa with intensive reaction of intraalveolar macrophages, alveolar lipoproteinosis persisting in some areas of the lung, and silicotic nodules of up to $1 \mathrm{~mm}$. Lymphocytic infiltrates already resolved. A great limitation for comparison of findings in transbronchial and surgical lung biopsies is the difference in the size of biopsy specimens, so a time progression of morphological changes could not have been correctly assessed.

According to the literature, increasing evidence shows that lung inflammation and apoptosis are hallmarks of acute silicosis ${ }^{14)}$. In animal models of acute silicosis, severe lung inflammation, alveolar lipoproteinosis, apoptosis, induction of reactive oxygen species, production of proinflammatory cytokine/chemokine, and tissue destruction were found ${ }^{14)}$. The accelerated acute inhalation model also led to the development of acute-like injury (e.g. apoptosis, inflammation, tissue destruction ${ }^{15)}$. Animal models have shown that genes regulating fibrosis, oxidative stress, and metalloproteases contribute to both acute and chronic silicosis, but proinflammatory cytokines are associated with acute but not chronic silicosis ${ }^{14)}$.

Radiographic findings in our patient comprised features of both acute and chronic silicosis, with the development of acute changes later in the course of disease. On initial presentation, HRCT scans showed only interstitial thickening, diffuse small nodules and mediastinal lymphadenopathy, characteristic for simple chronic silicosis. Apart from progression of these radiographic findings, ground-glass opacities and areas of consolidation typical for lipopro- 
teinosis appeared after $2 \mathrm{yr}$ follow-up.

Increased serum levels of tumour markers TK, TPA, 32-microglobulin, NSE and CYFRA 21-1 were observed in our patient. Also neoplastic diseases (e.g. lung cancer, lymphoproliferative disorders, lymphangitic carcinomatosis) were suspected in the current case due to the elevation of tumour markers. However, tumour was histologically found neither in biopsy samples nor at autopsy. Except for lung cancer, increased concentrations of tumour markers have been shown also in benign pulmonary diseases, but only few studies have evaluated the clinical significance of tumour markers in patients with silicosis ${ }^{16}$. In primary pulmonary alveolar proteinosis, an increase in CYFRA 21-1, carcinoembryonic antigen, CA 19-9, CA 15-3 and TPA was observed in serum and BALF ${ }^{17,}{ }^{18)}$. The elevation of tumour markers can be partly attributed also to the presence of secondary alveolar proteinosis in this case of accelerated silicosis. Recently a study has demonstrated increased serum concentrations of NSE and CA 125 in silicosis patients without malignancy ${ }^{16)}$. NSE and CA 125 levels were significantly correlated with spirometric parameters and LDH concentrations, thus predicting disease severity in silicosis patients ${ }^{16}$. These results support the finding of significantly increased levels of NSE in our case, whereas concentrations of CA 125 were in this patient normal. The mechanism of tumour markers' increase in silicosis patients without malignancy is unclear. It is speculated that increased serum NSE concentrations in silicosis may originate from hyperplasia of neuroendocrine cells in the silicotic lungs. The release of NSE into the peripheral circulation may be facilitated by the increased alveolocapillary membrane permeability ${ }^{16)}$.

Whole lung lavage (WLL) is considered to be a therapeutic option both in silicosis and pulmonary alveolar proteinosis. In silicosis patients WLL may remove large quantities of dust, soluble materials, and inflammatory cells from the lungs and relieve respiratory symptoms, but sustained improvement in lung function parameters has not been shown in a clinical trial ${ }^{1)}$. Several studies have reported WLL performed also in acute silicoproteinosis ${ }^{19},{ }^{20}$. Karnak et al. has described a case of acute silicoproteinosis treated with WLL leading to significant clinical, physiological and radiological improvement ${ }^{19}$ ). The patient had no recurrence of the disease after the treatment. In the study of Zhang et al. WLL has been shown as an effective therapy especially for early and accelerated silicosis, but WLL should be used cautiously in the treatment of advanced silicosis ${ }^{21)}$. Lower progression rate on chest X-ray, slower decrease of functional parameters, im- provement of the cough and expectoration were found in the group of silicosis patients treated with WLL ${ }^{21}$. However, in our case WLL brought no clinical or radiological improvement and functional findings worsened.

Lung transplantation (LT) is a potential alternative for end-stage silicosis, especially for young patients ${ }^{1,22,23)}$. LT for occupational lung diseases is relatively rare $^{23)}$. Patients with silicosis represent $0.5 \%$ to $5 \%$ of all candidates for $\mathrm{LT}^{23-26)}$. Singer et al. have reported a 2-fold increased mortality risk in subjects undergoing LT for occupational lung diseases ${ }^{23)}$. This risk of death was limited to the patients with non-silicotic occupational lung diseases in the first post-transplantation year. These observations differ from an earlier single-centre report of poorer post-LT survival of patients with silicosis in comparison with subjects with idiopathic pulmonary fibrosis ${ }^{23,27)}$. Unfortunately, in the current case of accelerated silicosis neither LT led to a therapeutical success.

\section{Conclusion}

In the current case, a rare diagnosis of accelerated silicosis was confirmed by diagnostic considerations and methods. Initially, the patient presented with progressive dry cough and exertional dyspnoea. Given his occupational history and known high-risk exposure to respirable silica particles in his profession of a sandblaster, a possible occupational aetiology was considered in the early diagnostic process. Eventually, this was confirmed by histological, clinical, hygiene and autopsy findings.

Although accelerated silicosis is a rare disease, it may be seen today, even in series of cases related to "new" professions such as denim sandblasting. An important factor is always massive exposure to respirable silica particles, frequently potentiated by unsatisfactory hygienic conditions in the workplace. Given the poor prognosis of this condition, its potential development in association with high-risk industries should not be underestimated. Careful prevention measures are necessary, in the form of both the maximum possible reduction of workers' exposure at the workplace and the use of suitable and effective protective equipment.

\section{Acknowledgements}

The authors thank to the patient's bereaved family for their consent with the publication of this case report. Supported by the Czech Ministry of Health (IGA MZ CR NT11117 and IGA LF_UP 2014_020). 


\section{References}

1) Leung CC, Yu ITS, Chen W (2012) Silicosis. Lancet 379, 2008-18. [Medline] [CrossRef]

2) Rees D, Murray J (2007) Silica, silicosis and tuberculosis. Int J Tuberc Lung Dis 11, 474-84. [Medline]

3) Castranova V, Vallyathan V (2000) Silicosis and coal workers' pneumoconiosis. Environ Health Perspect 108 Suppl 4, 675-84. [Medline] [CrossRef]

4) Rimal B, Greenberg AK, Rom WN (2005) Basic pathogenetic mechanisms in silicosis: current understanding. Curr Opin Pulm Med 11, 169-73. [Medline] [CrossRef]

5) Uptodate. Silicosis. http://www.uptodate.com/contents/ silicosis? source $=$ search result\&search $=$ silicosis\&selectedT itle=1\%7E22. Last review current through: Feb 2014.

6) Özkan M, Ayan A, Arik D, Balkan A, Ongürü O, Gümüş S (2009) FDG PET findings in a case with acute pulmonary silicosis. Ann Nucl Med 23, 883-6. [Medline] [CrossRef]

7) Chong S, Lee KS, Chung MJ, Han J, Kwon OJ, Kim TS (2006) Pneumoconiosis: comparison of imaging and pathologic findings. Radiographics 26, 59-77. [Medline] [CrossRef]

8) Ozmen CA, Nazaroglu H, Yildiz T, Bayrak AH, Senturk S, Ates G, Akyildiz L (2010) MDCT findings of denimsandblasting-induced silicosis: a cross-sectional study. Environ Health 9, 17 http://www.ehjournal.net/content/ pdf/1476-069X-9-17.pdf. [Medline] [CrossRef]

9) Alper F, Akgun M, Onbas O, Araz O (2008) CT findings in silicosis due to denim sandblasting. Eur Radiol 18, 2739-44. [Medline] [CrossRef]

10) Ladou J (2007) Current occupational and environmental medicine, 4th Ed., 326-327, Mc-Graw Hill Companies, USA.

11) Akgun M, Gorguner M, Meral M, Turkyilmaz A, Erdogan F, Saglam L, Mirici A (2005) Silicosis caused by sandblasting of jeans in Turkey: a report of two concomitant cases. J Occup Health 47, 346-9. [Medline] [CrossRef]

12) Tse LA, Li ZM, Wong TW, Fu ZM, Yu ITS (2007) High prevalence of accelerated silicosis among gold miners in Jiangxi, China. Am J Ind Med 50, 876-80. [Medline] [CrossRef]

13) Jiang CQ, Xiao LW, Lam TH, Xie NW, Zhu CQ (2001) Accelerated silicosis in workers exposed to agate dust in Guangzhou, China. Am J Ind Med 40, 87-91. [Medline] [CrossRef]

14) Langley RJ, Mishra NC, Peña-Philippides JC, Rice BJ, Seagrave JC, Singh SP, Sopori ML (2011) Fibrogenic and redox-related but not proinflammatory genes are upregulated in Lewis rat model of chronic silicosis. J Toxicol Environ Health A 74, 1261-79. [Medline] [CrossRef]

15) Porter DW, Ramsey D, Hubbs AF, Battelli L, Ma J, Barger M, Landsittel D, Robinson VA, McLaurin J, Khan A,
Jones W, Teass A, Castranova V (2001) Time course of pulmonary response of rats to inhalation of crystalline silica: histological results and biochemical indices of damage, lipidosis, and fibrosis. J Environ Pathol Toxicol Oncol 20 Suppl 1, 1-14. [Medline]

16) Fang SC, Zhang HT, Wang CY, Zhang YM (2014) Serum CA125 and NSE: biomarkers of disease severity in patients with silicosis. Clin Chim Acta 433, 123-7. [Medline] [CrossRef]

17) Trapnell BC, Whitsett JA, Nakata K (2003) Pulmonary alveolar proteinosis. N Engl J Med 349, 2527-39. [Medline] [CrossRef]

18) Hirakata Y, Kobayashi J, Sugama Y, Kitamura S (1995) Elevation of tumour markers in serum and bronchoalveolar lavage fluid in pulmonary alveolar proteinosis. Eur Respir J 8, 689-96. [Medline]

19) Karnak D, Köycü G, Erdemli E, Dizbay Sak S, Kağan Kadığlu Y (2011) Acute silicoproteinosis: therapy success. Respiration 82, 550-1. [Medline] [CrossRef]

20) Stafford M, Cappa A, Weyant M, Lara A, Ellis J Jr, Weitzel NS, Puskas F (2013) Treatment of acute silicoproteinosis by whole-lung lavage. Semin Cardiothorac Vasc Anesth 17, 152-9. [Medline] [CrossRef]

21) Zhang YM, Zhang HT, Wang CY, Wang W, Wu J, Wang C (2012) [Long-term therapeutic effects of whole lung lavage in the management of silicosis]. Zhonghua Lao Dong Wei Sheng Zhi Ye Bing Za Zhi 30, 690-3. [Medline]

22) Kramer MR, Blanc PD, Fireman E, Amital A, Guber A, Rhahman NA, Shitrit D (2012) Artificial stone silicosis: disease resurgence among artificial stone workers. Chest 142, 419-24. [Medline] [CrossRef]

23) Singer JP, Chen H, Phelan T, Kukreja J, Golden JA, Blanc PD (2012) Survival following lung transplantation for silicosis and other occupational lung diseases. Occup Med (Lond) 62, 134-7. [Medline] [CrossRef]

24) Burton CM, Milman N, Carlsen J, Arendrup H, Eliasen $\mathrm{K}$, Andersen CB, Iversen M, Copenhagen National Lung Transplant Group (2005) The Copenhagen National Lung Transplant Group: survival after single lung, double lung, and heart-lung transplantation. J Heart Lung Transplant 24, 1834-43. [Medline] [CrossRef]

25) Mao W, Chen J, Zheng M, Wu B, Zhu Y (2013) Initial experience of lung transplantation at a single center in China. Transplant Proc 45, 349-55. [Medline] [CrossRef]

26) Chida M, Fukuda H, Araki O, Tamura M, Umezu H, Miyoshi S (2010) Lung transplantation for aspirationinduced silicosis of the lung. Gen Thorac Cardiovasc Surg 58, 141-3. [Medline] [CrossRef]

27) Di Giuseppe M, Gambelli F, Hoyle GW, Lungarella G, Studer SM, Richards T, Yousem S, McCurry K, Dauber J, Kaminski N, Leikauf G, Ortiz LA (2009) Systemic inhibition of NF-kappaB activation protects from silicosis. PLoS ONE 4, e5689. [Medline] [CrossRef] 